\title{
EXPERIMENTAL AND NUMERICAL INVESTIGATION INTO EFFECT OF ELEVATED TEMPERATURE ON FRETTING FATIGUE BEHAVIOR
}

\author{
R. Hojjati Talemi ${ }^{1}$, M. Soori ${ }^{2}$, M. Abdel Wahab ${ }^{1}$ and P. De Baets ${ }^{1}$ \\ ${ }^{1}$ Department of mechanical construction and production, Faculty of Engineering, Gent University, Belgium \\ ${ }^{2}$ Department of mechanical engineering, Islamic Azad University, Takestan Branch, Takestan, Iran
}

\begin{abstract}
Fretting fatigue damage occurs in contacting parts when they are subjected to fluctuating loadings and sliding movements at the same time. This phenomenon may occur in many applications such as bearings/ shafts, bolted and riveted connections, steel cables, and steam and gas turbines. In this paper, the effect of elevated temperature on fretting fatigue life of Al7075-T6 is investigated using a new device for fretting fatigue tests with variable crank shaft mechanism. Also a finite element modeling method was used to estimate crack propagation lifetime in aluminum alloy, Al7075-T6 specimens at elevated temperature under fretting condition. In this method, shear and normal stresses that are caused by contact load are updated at each crack growth increment. Finally, a comparison between the experimental and numerical results is done in order to evaluate the FE simulation.

The experimental results show that: (i) fretting fatigue life of the material increases with temperature up to $350^{\circ} \mathrm{C}$ by $180 \%$ for low stresses and decreases by $40 \%$ for high stresses, (ii) this fashion of variation of fretting fatigue life versus temperature is believed to be due to degradation of material properties which occurs by overaging and wear resistance increase due to oxidation of aluminum alloy. While overaging gives rise to degradation of mechanical strength of material and hence the reduction of its fretting fatigue life, surface oxidation of the specimens brings some improvement of fatigue behavior of the material. Metallurgical examination of the specimens reveals that temperature results in precipitation of impurities of al-7075-T6. The size of precipitated impurities and their distances gets bigger as temperature increases. This could be a reason for material degradation of specimens which are exposed to heating for longer time duration.
\end{abstract}

Keywords Al7075-T6, Fretting Fatigue, Crack propagation, Overaging, Finite element

\section{INTRODUCTION}

Fretting is a wear phenomenon that occurs between two contacting surfaces having small amplitude oscillatory motion [1]. The formation of debris and their entrapment between the contacting surfaces are thought to be one of the origins of crack initiation and premature failure of the engineering components under fretting fatigue conditions. Fretting fatigue mechanism is complex and despite the fact that many attempts have so far been devoted to the study of this process, still there are numerous issues associates with this phenomenon which have remained to be clarified. This phenomenon is schematically shown in Figure 1. Fretting fatigue may occur in mechanical components such as fasteners, turbine blades, bearings/ shafts, steel cables, steam and gas turbines [1]. The aviation industry is another area in which fretting fatigue failures are commonly observed.

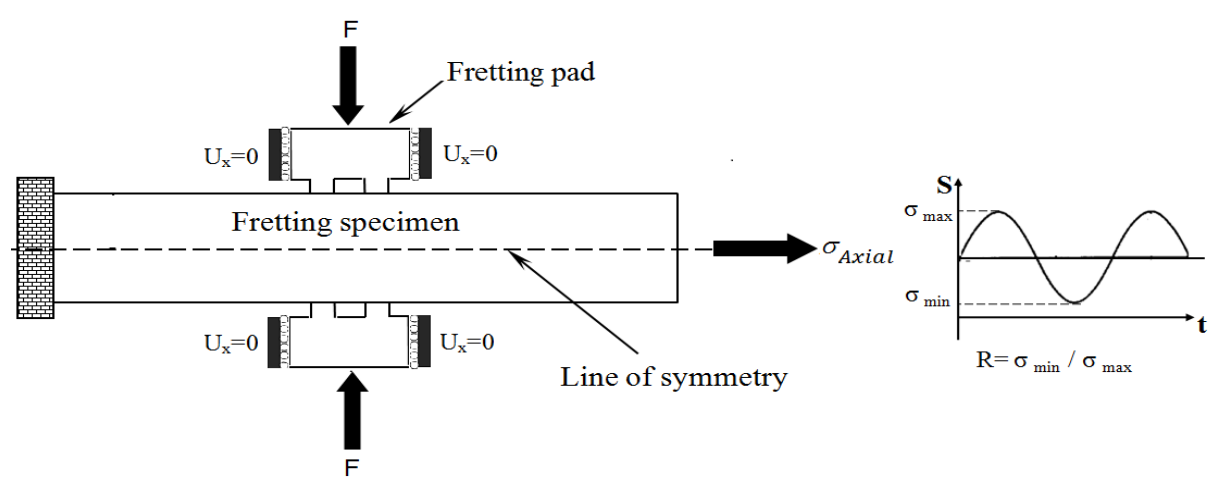

Figure 1. Schematic illustration of fretting fatigue. 
Fretting fatigue in turbine dovetails is shown in Figure 2 [2]. Fretting fatigue may reduce the endurance limit of a component by half or more, in comparison to the normal fatigue conditions. Wear and fretting cracks are two direct consequences of fretting fatigue. Figure 3 shows deep pitting in the contact zone of two specimens under fretting fatigue conditions.

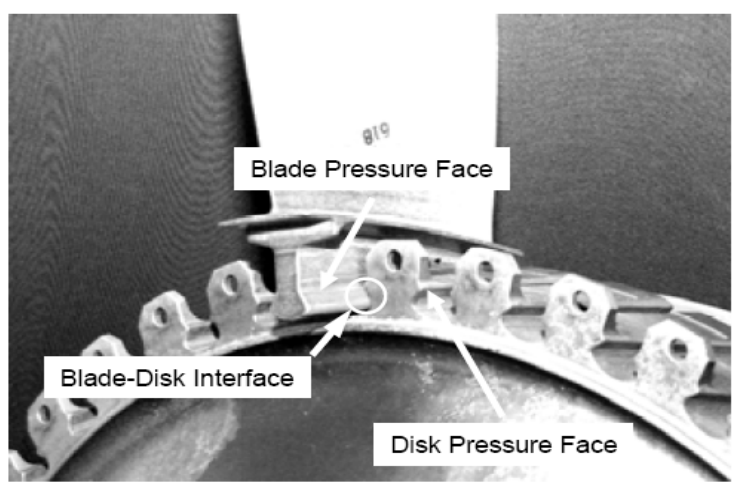

Figure 2. Fretting fatigue in turbine dovetails [2].

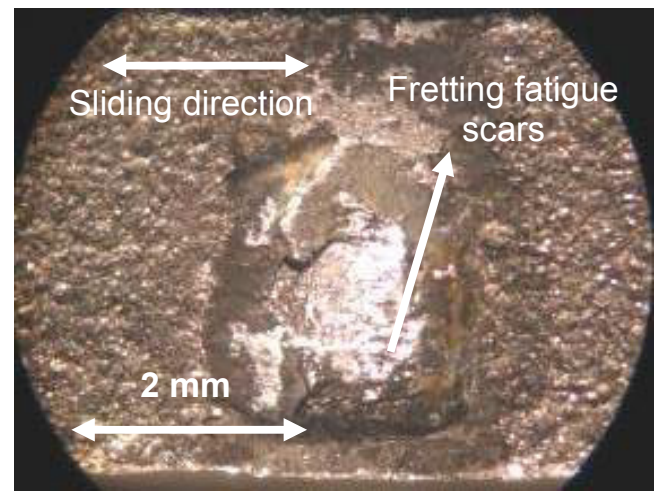

Figure 3. Deep pitting in the contact zone of two specimens under fretting fatigue conditions [3].

Figure 4 shows a fracture surface of a specimen after failure by fretting fatigue [3]. The figure clearly indicates that the fracture surface consists of three deferent regions; a fretting fatigue zone created by crack propagation, a crack growth zone and a tensile region which gives rise to fracture of specimen when it is sufficiently weakened by the crack zone development. It is generally thought that crack initiation is governed primarily by the local contact stresses and slips amplitude, whereas propagation is more related to the far-field or bulk stresses [1]. A micrograph of fretting crack propagation in a stainless steel alloy is depicted in Figure 5 . The crack trajectory can be explained by stress intensity factors $K_{l}$ and $K_{l l}$. Cracks initially grow oblique to the direction of normal force [4] (see figure 5). At this stage, which corresponds to a gross slip conditions between contacting surfaces, the effect of friction force prevails and $K_{/ /}$is the dominant mode of fracture. After the initial oblique propagation, the angle of crack gradually reduces and finally crack coincides with normal force direction. This stage corresponds to a state of partial slip in which a combination of the effects of modes $K_{l}$ and $K_{l /}$ takes place. In the third stage, crack grows perpendicular to the normal load direction, due to tensile stress, only by mode $K_{l}$.

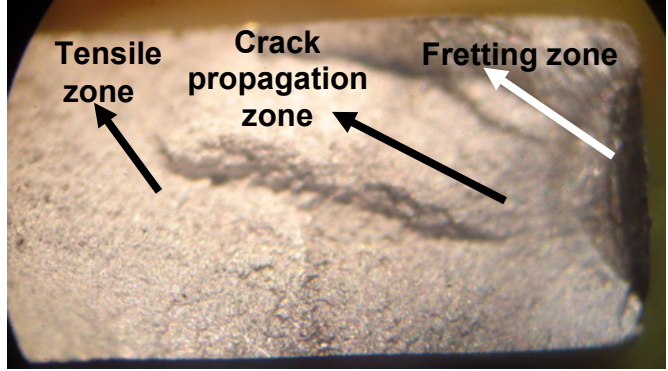

Figure 4. Fracture surface of a specimen after failure by fretting fatigue [3].

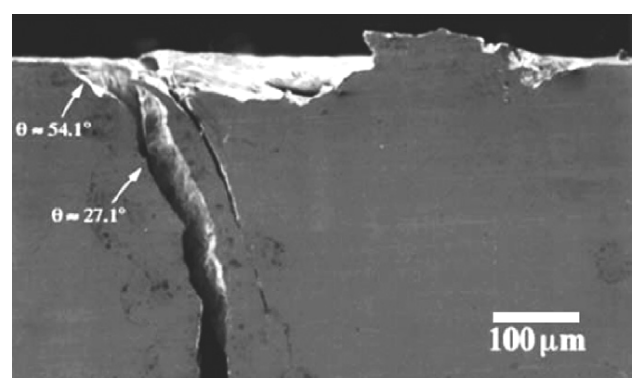

Figure 5. A micrograph of a fretting crack propagation in a stainless steel alloy [4]

Fretting fatigue life can be affected by many parameters such as contact pressure, $F$, axial stress, $\sigma$, friction between the pads and the specimen, pad geometry, sliding amplitude and temperature. The effect of heating on fretting fatigue has sufficiently been studied by different researchers [5,6]. Fretting fatigue behavior of materials at elevated temperatures while being influenced by temperature is not the same for all materials. Hamdy and Waterhouse [7] have shown that mechanical strength of Ti-6Al-4V at temperatures up to $600^{\circ} \mathrm{C}$ diminishes as temperature increases. Hamdy and Waterhouse [5] reported that fretting fatigue life of aged Inconel 718 at elevated temperatures up to $600^{\circ} \mathrm{C}$ was the same as that for normal fatigue at room temperature. Fretting fatigue life of materials has been examined by different authors such as Mutoh and Satoh [6] and Jina et al [8].

In this work, the effect of elevated temperature on fretting fatigue life of Al7075-T6 is investigated. Also it is known that the study of the influence of various parameters on fretting fatigue behavior of materials is costly and time consuming, numerical simulation is a cheap and easy to use tool by means of which fretting 
fatigue phenomenon can be characterized. Thus, the effect of temperature is studied using numerical codes such as ABAQUS [9] and FRANC2D/L [10]. Finally, the numerical results are validated by fretting fatigue tests.

\section{EXPERIMENTS}

\subsection{Material and specimen}

The specimen is machined from aluminum 7075-T6 forged plates by wire electrical discharge method. The longitudinal tensile properties (along the loading axis) were determined, i.e., the elastic modulus was 70 GPa and yield strength was $502 \mathrm{MPa}$. The specimen shown in Figure 6 had a width of $14.5 \mathrm{~mm}$, a thickness of $4.5 \mathrm{~mm}$ and a gauge length of $70 \mathrm{~mm}$. The pads are made of stainless steel 410 with yield and ultimate strength of 420 and $700 \mathrm{MPa}$, respectively. Each pad has two bases (contacting surfaces) through which the load is exerted on the specimen. The bases have a thickness of $3.1 \mathrm{~mm}$ and a length of $12 \mathrm{~mm}$ (figure 7).
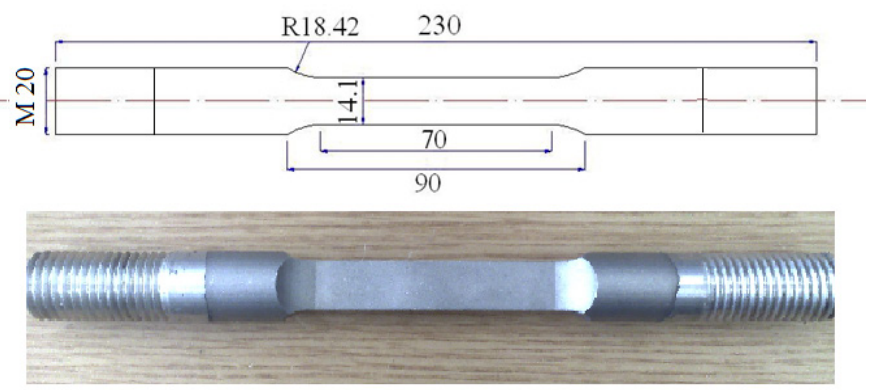

Figure 6. Flat specimens used for fretting fatigue tests.

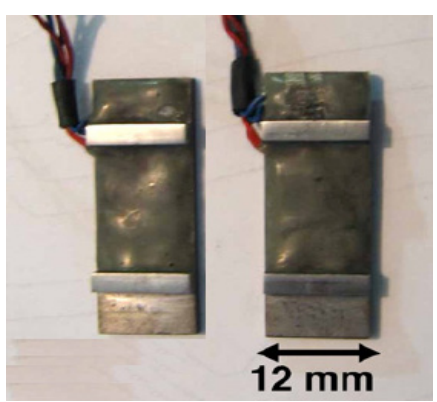

Figure 7. Pad used in the experiments.

\subsection{Test setup and procedure}

The fretting fatigue testing device used in this work has been developed by Majzoobi and Hojjati et al. [11]. A general view of the device and its diagrammatic representation are illustrated in Figure 8 . The axial fluctuating load is applied to the specimen by a variable crank mechanism. The mechanism consists mainly of a stepped eccentric shaft and two suspension plates [11]. The contact loading system, shown in Figure 9 , is completely embedded in the lower cross head which is supported by the two main columns of the device and can be moved vertically. The contact loading system consists of two pads, two adjusting screws and two load cells.

The contact load is induced by two adjusting screws and is measured using two load cells. The load cell readings can ensure that the contact loads produced by tightening screws in two opposite directions are equal. The contact is of the type of flat on flat. The pads are constrained to move vertically as this may affect the sliding oscillations between specimen and pads.

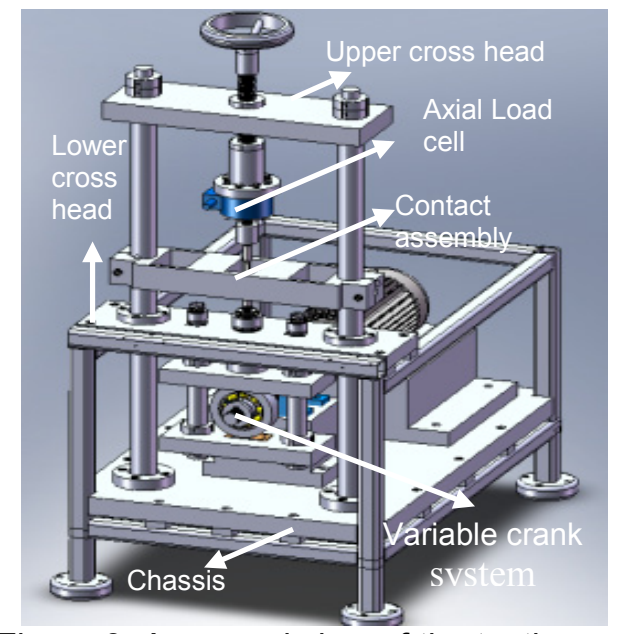

Figure 8. A general view of the testing device [11].

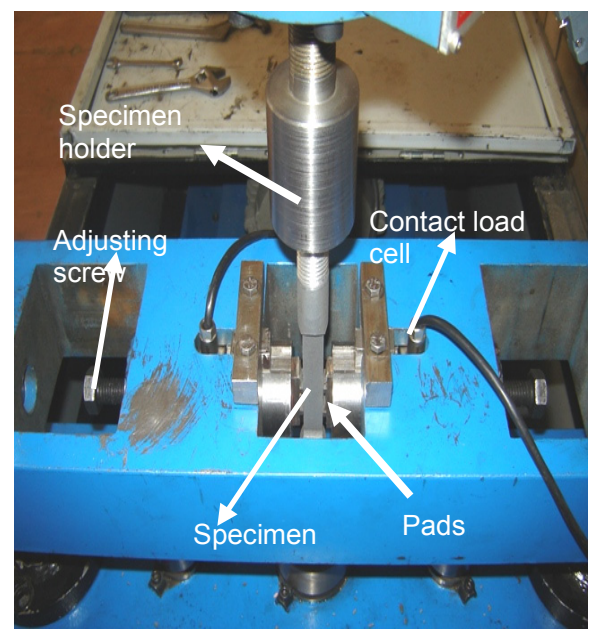

Figure 9. Contact loading system of the testing device [11]. 
Two load cells are mounted between the adjusting screws and the pads (see figure 9) monitor the contact load on separate digital displays. The frequency of the device can vary using an inverter up to a maximum of $25 \mathrm{~Hz}$. Two heating blowers on each side of the specimen were used to achieve the test temperature (Figure 10). The test temperature was measured and controlled using K-type thermocouples attached on the pad surface and monitored with digital display (Figure 11). Since the temperatures at the contact area and pads might be different, each test was conducted after measuring temperatures on the specimen and pads using a temperature calibration specimen. Before each test, the specimen was kept at $260^{\circ} \mathrm{C}$ for about an hour to have a uniform temperature distribution over the gauge area of encompassing the contact area. Further details about test setup can be found in reference [11]. The experiments are conducted for stress ratio, $R=0.1$, frequency of $25 \mathrm{HZ}$ at a constant force of $F=1200 \mathrm{~N}$, and working stresses of 110 , 150, 200 , and $280 \mathrm{MPa}$. Furthermore, in order to validate the fretting fatigue tests results a number of tensile tests were conducted on specimens at different temperatures and the ultimate strength of material was measured. For each temperature, the specimens were heated up in a furnace for different time durations. This is because the duration of fatigue tests depends on stress level and for low stresses; the specimens are exposed to heating for longer time. Also fractography of fractured surfaces and metallography are performed using optical microscopy.

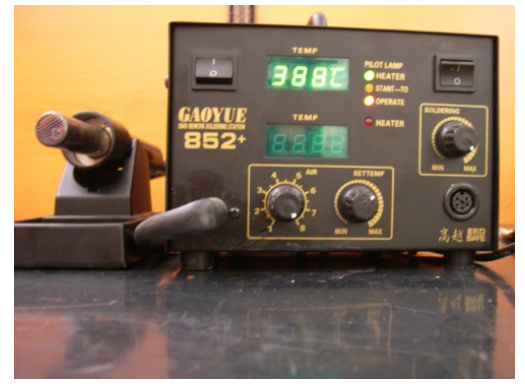

Figure 10. Heating blower

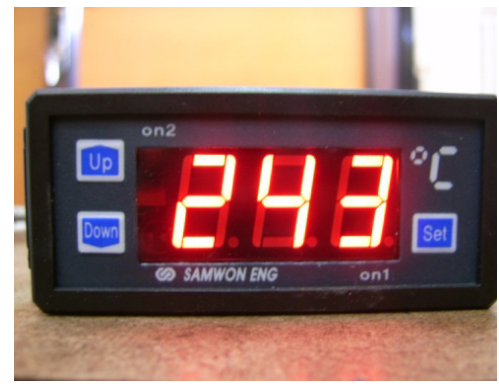

Figure 11. Temperature display

\subsection{Test results}

The results of fretting fatigue tests on heated specimens and variation of fretting fatigue life versus maximum stress in each temperature is illustrated in Figures 12 and 13. It can be clearly observed that fretting fatigue life increases with temperature for low stresses and decreases for high stresses. This fluctuation in fretting fatigue life versus temperature is thought to be basically due to degradation of material properties which occurs by overaging and wear resistance increase due to oxidation of aluminum alloy. This can be explained more by the fact that aluminum comes in heat-treatable and non-heat treatable alloys. Heat treatable aluminum alloys get their strength from a process called ageing. While the workability index in the 7075 alloy is improved approximately $50 \%$ by over-aging, significant decrease in tensile strength can occur when aluminum is subjected to over-aging.

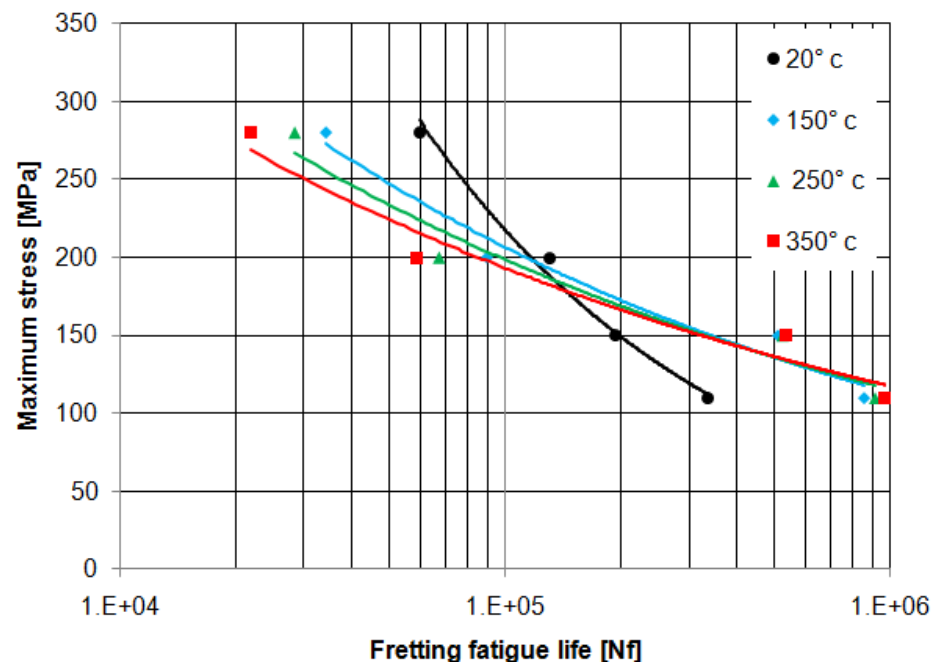

Figure 12. Maximum stress versus fretting fatigue life for different temperatures 


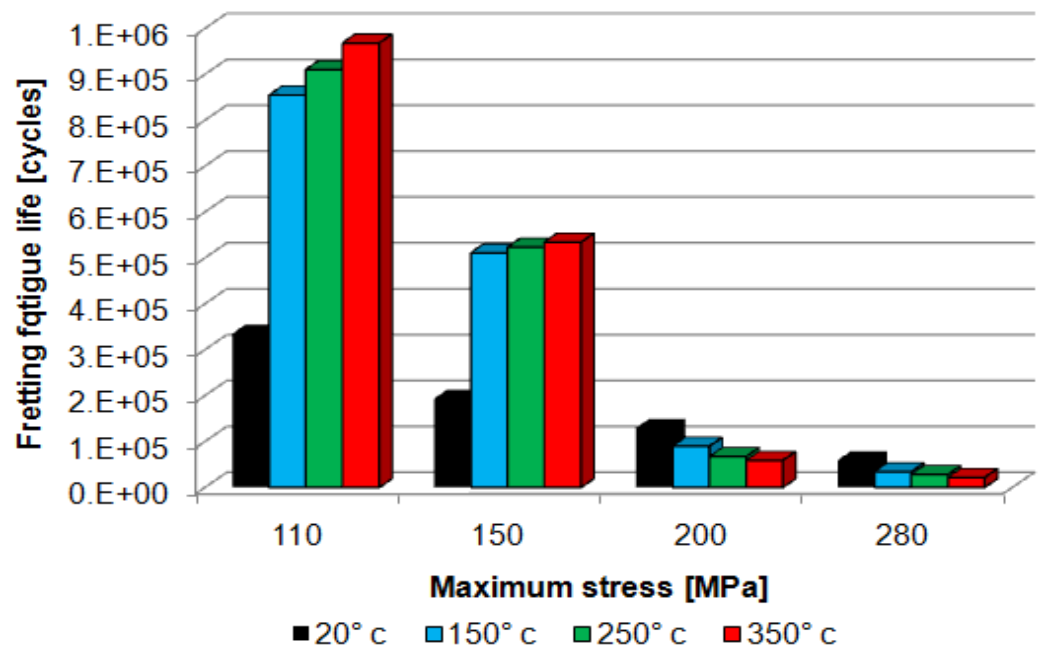

Figure 12. Maximum stress versus fretting fatigue life for different temperatures

After process of heating the material is ductile, since no precipitation has occurred. After a time the solute material precipitates and hardening develops. As the composition reaches its saturated normal state, the material reaches its maximum hardness. The precipitate, however, continues to grow. The fine precipitates disappear. They have grown larger, and as a result the tensile strength of the material decreases. This is called overaging. The tensile strength variation during aging and overaging are shown in Figure 14. While overaging gives rise to degradation of mechanical strength of material and hence the reduction of its fretting fatigue life, surface oxidation of the specimens brings about improvement of fatigue behavior of the material. From the tensile tests the variation of the ultimate strength shows that strength of material decreases as temperature rises (Figure 15).

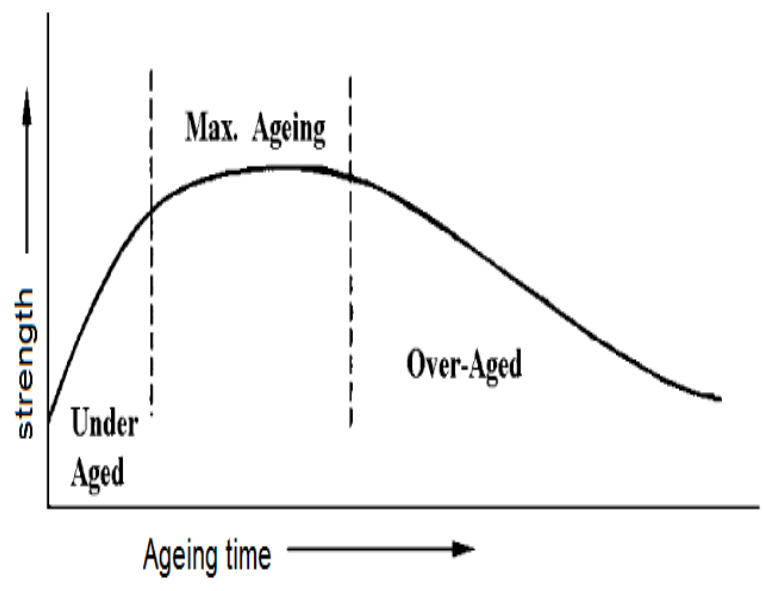

Figure 14. The effect of ageing on strength of aluminum

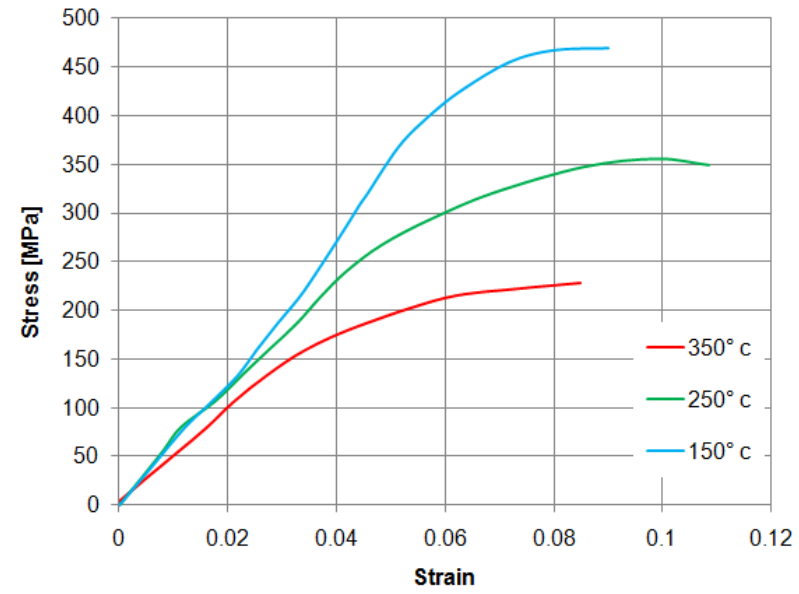

Figure 15. Stress versus strain curve for deferent temperatures

Optical examination of the specimens in Figure 16 reveals that temperature results in precipitation of impurities of al-7075-T6. The size of precipitated impurities and their distances gets bigger as temperature increases. This could be a reason for material degradation of specimens which are exposed to heating for longer time duration. However, to the best of authors' belief, the ageing phenomenon can be recognized as the most effective parameter and responsible for the reduction of fretting fatigue life of specimens at high stresses and at low stresses oxidation of aluminum alloy at contact surface of specimen and pad plays as a lubricant role that causes a significant rise in fretting fatigue life. 

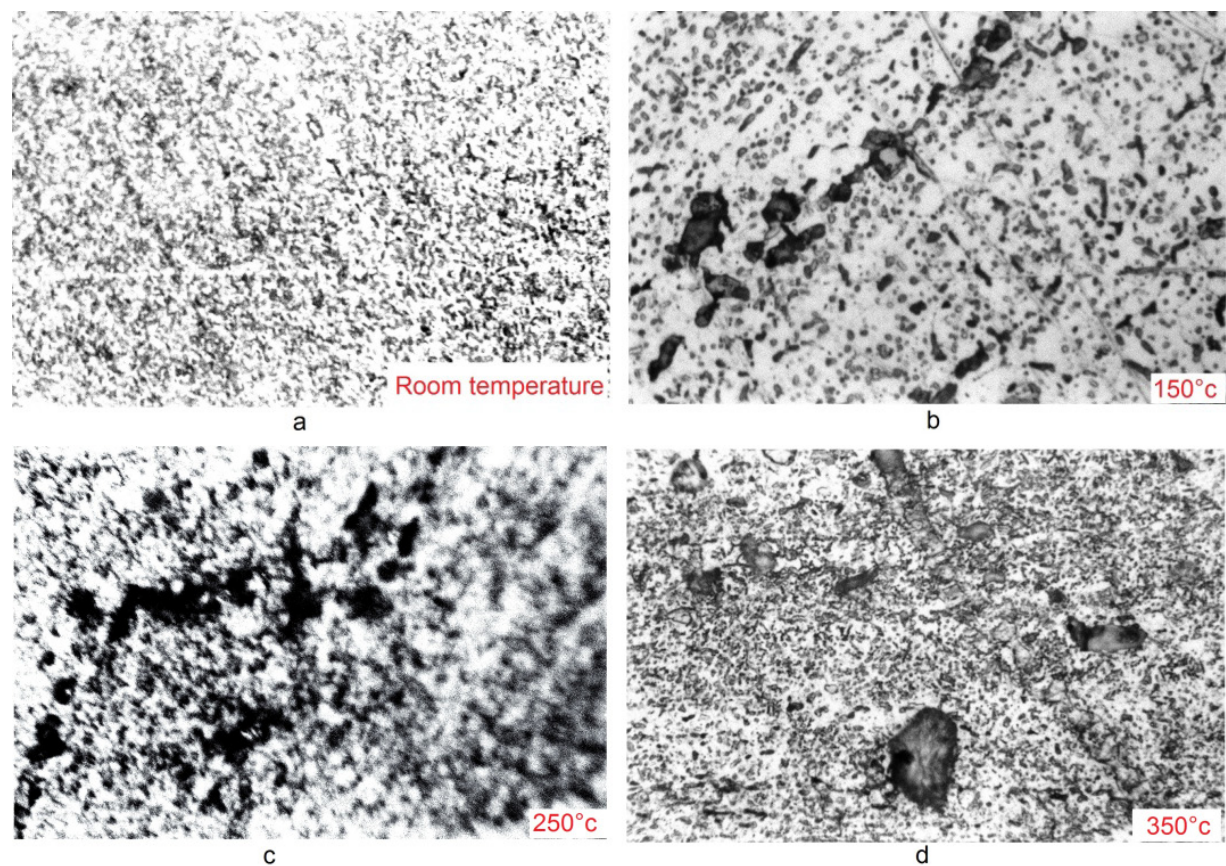

Figure 16. The microstructure of the material (a) at $20^{\circ} \mathrm{C}$, (b) at $150^{\circ}$,

(c) at $250^{\circ} \mathrm{C}$ and (d) at $350^{\circ} \mathrm{C}$ for 12 hours (magnification $\times 1000$ )

Fractured surfaces of tested specimens were examined using optical microscopy. Some typical results are illustrated in Figures.17 and 18 for different temperatures at different stresses. As the figures suggest, the fracture surfaces typically consist of two different regions; a fatigue zone created by crack propagation and a tensile region which gives rise to fracture of specimen when it is sufficiently weakened by the crack zone development.

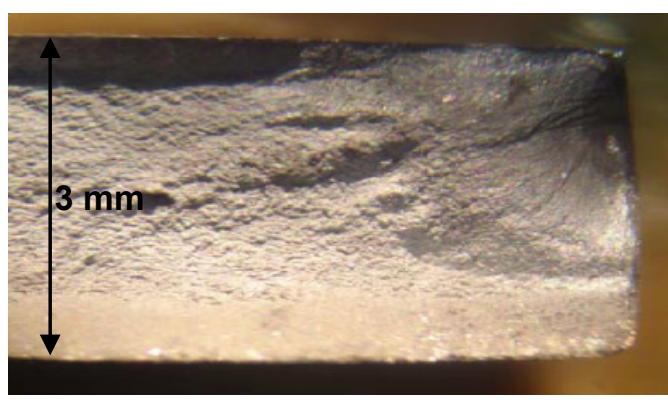

Figure 17. Fracture surface of specimen at stress of $110 \mathrm{MPa}$ and $350^{\circ} \mathrm{C}$

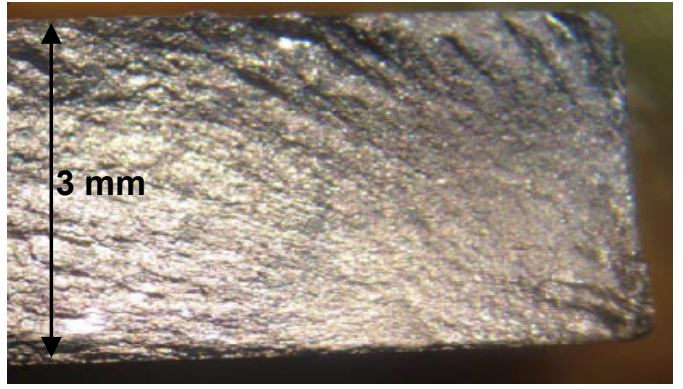

Figure 18. . Fracture surface of specimen at stress of $280 \mathrm{MPa}$ and $250^{\circ} \mathrm{C}$

\section{NUMERICAL SIMULATIONS}

\subsection{Finite element analysis}

A commercial finite element code, ABAQUS [9], was used to analyse the specimen without crack under a given loading condition as a first step. This analyse was done in order to predicate location of initial crack for crack propagation analyse, since previous studies suggests that the location of fretting fatigue crack initiation corresponds with a maximum value of $\sigma_{x x}[1,12]$. The finite element model for flat pad is shown in Figure 19. Note that only one-quarter of the test configuration is considered due to double symmetry with respect to the $X$ and $Y$ axes. Along with the "master-slave" interfacial algorithm developed for contact modelling in the finite element code, ABAQUS, the four-node plane strain elements were utilized. The Lagrange multiplier of friction was used. First, specimens were analyzed using the contact force, $F / 2$ and the axial stress, $\sigma_{a x i l}$. These were applied to the finite element model in the three steps. In the first step, the contact force, $F / 2$ was applied to establish contact between pad and specimen. In the second and third steps, either the maximum bulk stress, $\sigma_{\text {Max }}$ or the minimum bulk stress, $\sigma_{\text {Min }}$, were applied, respectively. In order to have more accurate results, the finite element mesh was refined in the contact region. An acceptable element size was determined to be at least $9 \mu \mathrm{m} \times 9 \mu \mathrm{m}$ in the refined contact zone from the 
convergence study [13]. The fretting fatigue crack propagation was thereafter conducted using the finite element code, FRANC2D/L [10]. For this purpose, the same geometry and boundary conditions as used in ABAQUS code including the contact interface was modeled. The contact was defined with a gap element using a new material at interface of pad and specimen, with coefficient of friction equal to 0.5 . This means that in each step for crack propagation the effect of contact pad was considered and the stress intensity factors were updated after each crack increment. This proposed technique would solve most problems in previous studies where sub-modeling was used for crack propagation [13]. Then, the temperature distribution also was generated on material-by-material basis which has capability to assign different coefficient of thermal expansion and one temperature for the entire model [10]. Finally, an edge crack was inserted in the model considering the contact to perform the crack growth analysis by FRANC2D/L code, which has capability for incremental crack growth using fracture mechanics principles as elaborated later.

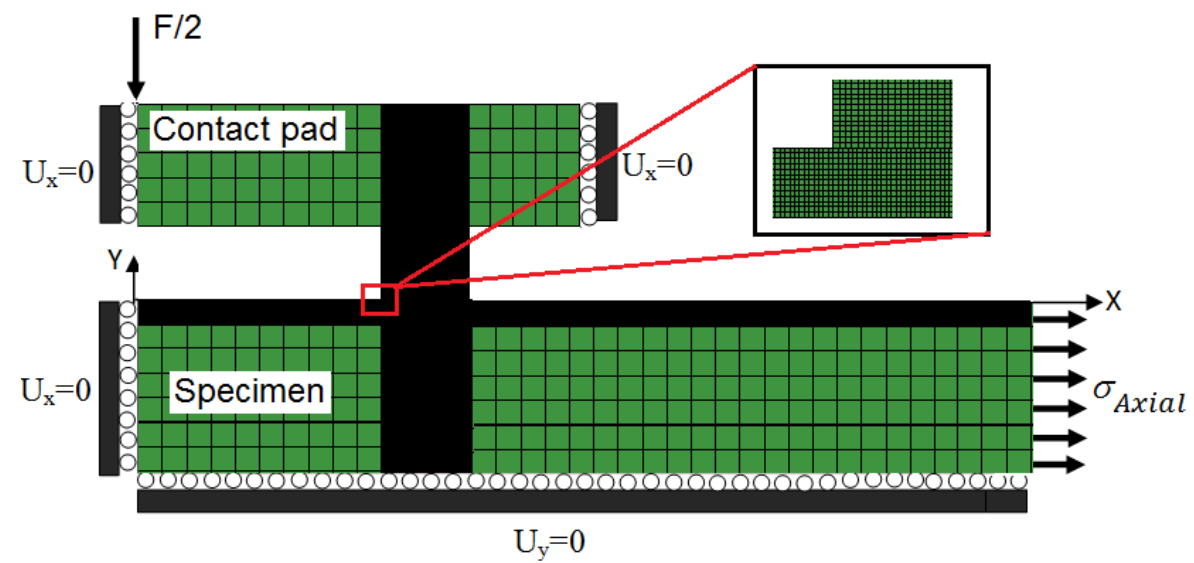

Figure 19. The schematic illustration of finite element model of fretting Fatigue assembly.

\subsection{Crack propagation analysis}

The crack propagation needs the location, length and orientation of the initial crack. As mentioned above the location of initial crack extract from the FE model using ABAQUS code where the maximum value of $\sigma_{x x}$ takes place, the length and the orientation of the crack propagation path was represented by a curvilinear path consisting of, S, straight segments, as shown in Figure 20 . In the first step, an initial crack of length, $\left(I_{0}\right.$ $=0.01 \mathrm{~mm})$, with an orientation, $\left(\theta_{1}=45^{\mathrm{m}}\right)$ from the $y$-axis was introduced on the contact surface which is observed from previous experimental studies results [14]. The analysis was then performed with a crack length increment of $\Delta l$. The incremented crack kinked at the tip of the initial crack at $\left(x_{2}, y_{2}\right)$ to produce a new crack at a slope of $\theta_{2}$ in the second step of the analysis, and this process was continued.

In FRANC2D/L, the mesh is modified in each incremental step using the Suhara-Fukuda algorithm [15]; the algorithm generates a mesh of triangular elements as shown in Figure 21, and the new crack geometry is represented at each incremental step to reflect the current crack configuration. Along with other theories, the code uses the maximum tangential stress theory, proposed by Erdogan and Sih [16], to determine the crack growth direction. The crack angle, $\theta_{i}$ at the ith step was computed by

$$
\theta_{i}=\theta_{i-1}+2 \tan ^{-1}\left[\frac{K_{\text {IMax }}-\sqrt{K_{\text {IMax }}+8 K^{2} \text { IIMax }}}{4 K_{\text {IIMax }}}\right]
$$

Where $K_{I M a x i}$ and $K_{I I M a x i}$ are the maximum stress intensity factors at the ith step corresponding to the two crack propagation modes, Mode I and Mode II, at the maximum load. In this way crack trajectory was developed incrementally for a given loading condition using maximum tensile stress criterion. Further, the crack growth rate was assumed to be governed by the Mode I stress intensity factors, $K_{I \operatorname{Max}}$ and $K_{I \min }$ [17]. The modified crack closure integral technique of Rybicki and Kanninen [18] was used to calculate these stress intensity factors. These values were then used with the sigmoidal crack growth model to determine the crack propagation life. $\Delta /$ was considered $0.1 \mathrm{~mm}$ for crack propagation. Final failure occurs when the value of stress intensity factor, $K_{l}$ tends to its critical value, $K_{I C}$. 


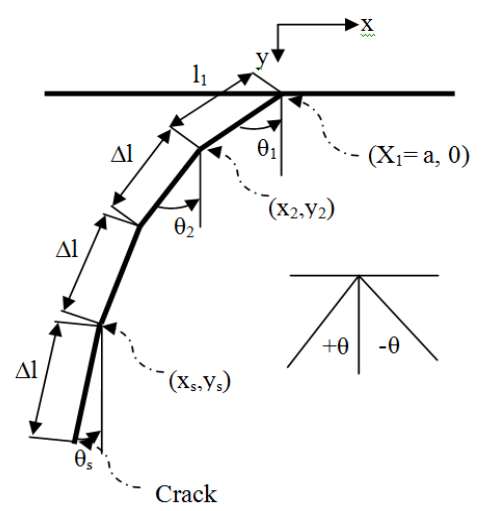

Figure 20. Trajectory of crack growth

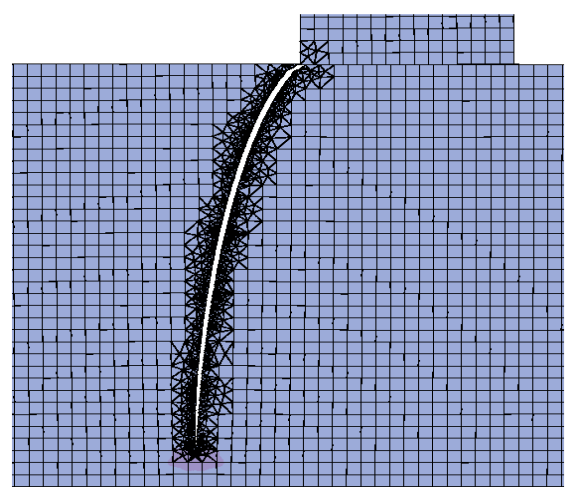

Figure 21. An initial crack in FRANC2D/L and triangular elements around the crack.

FRANC2D/L CRACK GROWTH (N40_F2DL_CG) code was used in order to predict the crack growth life time curve. This program, realized by Domenico [19], calculates crack growth life in generic 2D layered structures. The core of the program is Franc2D/L (based on Franc2D, Copyright (C) Paul 'Wash' Wawrzynek and Tony Ingraffea) [10], which is used to extract stress intensity factors (SIF) history files for generic geometries and sets of loads. N40_F2DL_CG imports SIF history files and integrates the material da/dN equation (NASGRO model) for calculating crack growth for variable amplitude spectrum of loads. FRANC2D/L CRACK GROWTH code is able to show the amount of KI, KII andK in every increment of crack propagation and it is designed to deal with Forman NASGRO material models (equation 2). The elements of the NASGRO crack growth rate equation were developed by Forman and Newman at NASA, and it has been implemented in FRANC2D/L CRACK GROWTH as follows [20]:

$$
\frac{d a}{d N}=C\left[\frac{(1-f)}{(1-R)} \Delta K\right]^{n} \frac{\left(1-\frac{\Delta K_{t h}}{\Delta K}\right)^{p}}{\left(1-\frac{K_{\text {max }}}{K_{\text {crit }}}\right)^{p}}
$$

Where $C, n, p$ and $q$ are empirical constants, which are obtained by curve fitting the test data and $f$ is the ratio of crack opening SIF to maximum SIF. The value of $f$ is related to stress (load) ratio, flow stress and the plane stress/strain constraint factor. These values are provided by the FRANC2D/L CRACK GROWTH material database for each material. It is worth mentioning that $\Delta K_{t h}$ is not a simple threshold stress intensity range for long crack, but it includes the effect of short crack by involving 'intrinsic crack length', and the parameter $f$. Also $C=6 \times 10^{-10}$ and $n=2.51$ was used as fatigue ductility exponent [21], hence number of the cycles $(d N)$ for a crack grow $(d a)$ in each increment, can be computed. Finally, the specimen fracture life was obtained.

\subsection{Finite element results and the effect of temperature on crack propagation}

Figure 22 reveals the stress contours for Von-Mises stress. It is interesting to note that the maximum vonMises stress occurs near the sharp edge contact between the pad and the specimen. The simulations were validated by making a comparison between the number of cycles as predicted by numerical simulations in this work and the experimental measurements using replica. The results are shown in Figure 23 for different stress at temperature $150^{\circ} \mathrm{C}$. As the results suggest a maximum of $22 \%$ difference is observed that is quite normal in fatigue context. 


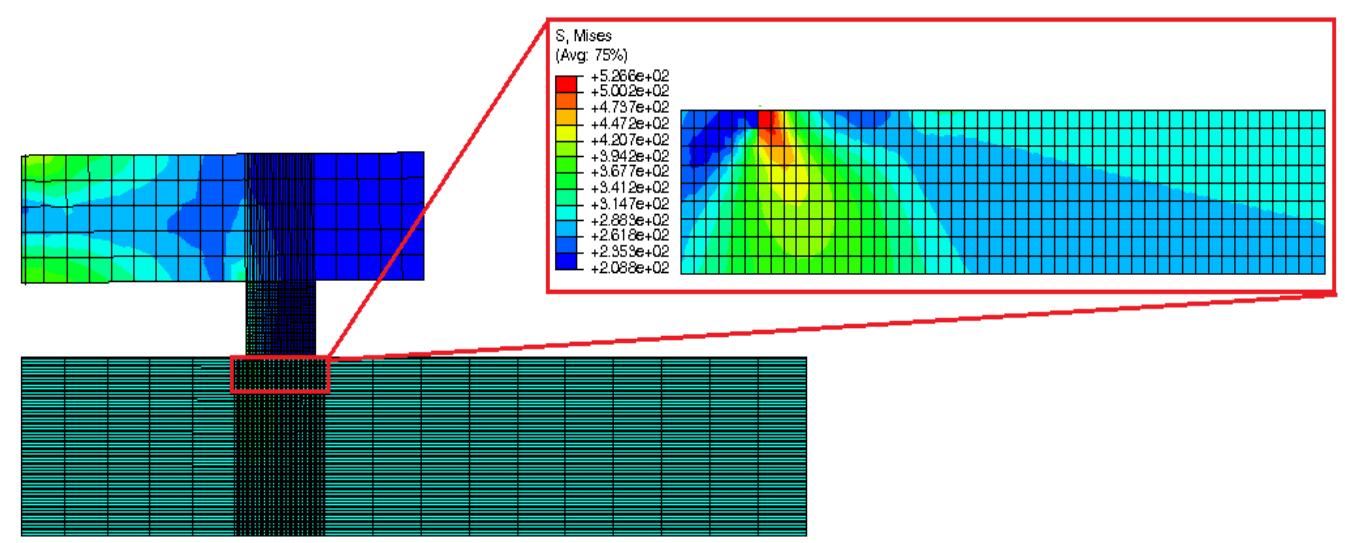

Figure 22. von-Mises equivalent stress distribution of fretting pairs $\left(\sigma_{\text {axial }}=280\right.$ Mpa and $\left.\mathrm{F}=1200\right)$

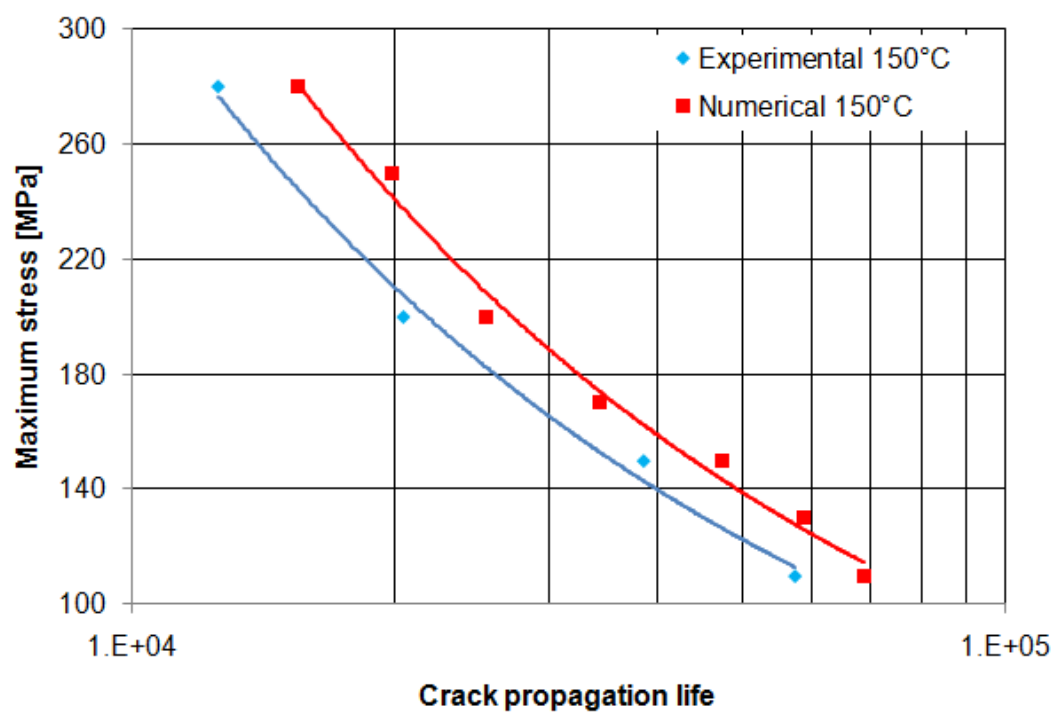

Figure 23. A comparison between experimental and numerical crack growth

\section{CONCLUSIONS}

The experimental results reveal that fretting fatigue life of the material increases with temperature by $180 \%$ for low stresses and decreases by $40 \%$ for high stresses This fashion of variation of fretting fatigue life versus temperature is believed to be due to degradation of material properties which occurs by overaging and wear resistance increase due to oxidation of aluminum alloy. While overaging gives rise to degradation of mechanical strength of material and hence the reduction of its fretting fatigue life, surface oxidation of the specimens brings about improvement of fatigue behavior of the material. The variation of the ultimate strength versus temperature that is obtained from the tensile tests reveals the same trend as observed for fretting fatigue life versus temperature at different stress levels. Metallurgical examination of the specimens reveals the size of precipitated impurities and their distances gets bigger as temperature increases. This could be a reason for material degradation of specimens which are exposed to heating for longer time duration.

Numerical simulation of fretting fatigue was performed using Abaqus and FRANC2D/L codes. The former predicts the normal and tangential contact stress distributions and the latter calculates the number of cycles required for a known crack propagation rate at elevated temperature. The calculation of cycles is based on Forman NASGRO equation when $\Delta K$ is computed by FRANC2D/L then it is possible to predict the cycles for a specific value of crack growth. The results indicate that the numerical simulations are capable of prediction the crack growth cycles and orientation at different stresses and temperatures. The computed crack propagation lives were compared to the results of experimental study where total fatigue life was measured. 


\section{ACKNOWLEDGEMENTS}

The authors wish to thank the Ghent University for the financial support received by the Special Funding of Ghent University (Bijzonder Onderzoeksfonds), in the framework of BOF project (BOF 01N02410).

\section{REFERENCES}

[1] Hills DA, Nowell D. Mechanics of fretting fatigue. Kluwer Academic Publisher, 1994.

[2] Shin. Ki S. Prediction of fretting fatigue behavior under elastic-plastic conditions. Mechanical Science and Technology 2009;23:2714-2721.

[3] Majzoobi GH, Ahmadkhani AR. The effects of multiple re-shot peening on fretting fatigue behavior of Al7075-T6. Surface \& Coatings Technology 2010;205(1):102-109.

[4] Stachowiak GW, Batchelor AW. Engineering Tribology. Butterworth Heinemann publisher, 2001.

[5] Hamdy MM, Waterhouse RB. The fretting wear of ti-6al-4v and aged inconel 718 at elevatedtemperatures. Wear 1981;71(2):237-248.

[6] Mutoh Y, Satoh T. High temperature fretting fatigue. Mechanical Engineering Publication, 1994.

[7] Hamdy MM, Waterhouse RB. The fretting fatigue behaviour of Ti-6A1-4V at temperatures up to 600 ${ }^{\circ} \mathrm{C}$. Wear 1979;56:1-8.

[8] Jina, O., Mallb S, Sahanb O. Fretting fatigue behavior of Ti-6Al-4V at elevated temperature. Int J Fatigue 2005;27:395-401.

[9] ABAQUS v 6.10, Standard User Manual, 2010.

[10] FRANC2D/L. A crack propagation simulator for plane layered structures. Engineering SoCaE, editor. Ithaca, New York Cornell University, 1998.

[11] Majzoobi GH, Hojjati R, Nematian M, Zalnejad E, Ahmadkhani AR. A new device for fretting fatigue testing. Transactions of The Indian Institute of Metals 2010;63(2-3):5.

[12] Ruiz C, Boddington PHB, Chen KC. AN INVESTIGATION OF FATIGUE AND FRETTING IN A DOVETAIL JOINT. Experimental Mechanics 1984;24(3):208-217.

[13] Fadag HA, Mall S, Jain VK. A finite element analysis of fretting fatigue crack growth behavior in Ti6AI-4V. Eng Fract Mech 2008;75(6):1384-1399.

[14] Lykins CD, Mall S, Jain V. A shear stress-based parameter for fretting fatigue crack initiation. Fatigue Fract Eng Mater Struct 2001;24(7):461-473.

[15] Shaw RD, Pitchen RG. MODIFICATIONS TO SUHARA-FUKUDA METHOD OF NETWORK GENERATION. International Journal for Numerical Methods in Engineering 1978;12(1):93-99.

[16] Erdogan F, Sih G. On the crack extension in plates under plane loading and transverse shear. Journal of Basic Engineering Trans ASME 1963;85(4):519-527.

[17] Shkarayev S, Mall S. Computational modelling of shot-peening effects on crack propagation under fretting fatigue. The Journal of Strain Analysis for Engineering Design 2003;38(6):495-506.

[18] Rybicki EF, Kanninen MF. A finite element calculation of stress intensity factors by a modified crack closure integral. Eng Fract Mech 1977;9(4):931-938.

[19] Quaranta D. FRANC2D/L CRACK GROWTH: A crack propagation simulator for plane layered structures (based on Franc2D, Copyright (C) Paul 'Wash' Wawrzynek and Tony Ingraffea). Ltd PA, editor. Switzerland.

[20] Forman RG, Mettu SR. Behavior of Surface and Corner Cracks Subjected to Tensile and Bending Loads in Ti-6Al-4V Alloy. Fracture Mechanics 22nd Symposium, Vol. 1 Philadelphia: ASTM STP 1131, H.A. Ernst, A. Saxena and D.L. McDowell, eds., American Society for Testing and Materials, 1992.

[21] Wang QY, Pidaparti RM. Static characteristics and fatigue behavior of composite-repaired aluminum plates. Composite Structures 2002;56(2):151-155. 